International Review of Research in Open and Distributed Learning Volume 16, Number 1

February - 2015

\title{
Open Informational Ecosystems: The Missing Link for Sharing Educational Resources
}

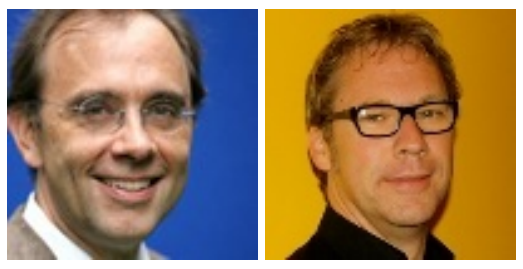

Michael Kerres and Richard Heinen

University Duisburg-Essen, Germany

\begin{abstract}
Open educational resources are not available "as such". Their provision relies on a technological infrastructure of related services that can be described as an informational ecosystem. A closed informational ecosystem keeps educational resources within its boundary. An open informational ecosystem relies on the concurrence of independent stakeholders that jointly provide (meta-) information also beyond its boundaries. Mechanisms of open informational ecosystems are described and how they contribute to the delivery of educational resources and to opening education. The paper describes the case of the German Bildungsserver that aims at establishing a federated network of providers of open and closed educational resources. It points out that the design of (inter-)national informational ecosystems has a major influence on the future of open educational resources in education.
\end{abstract}

Keywords: Informational infrastructure; ecosystems; OER 


\section{Why Ecosystems?}

Educational resources are not just available to learners. Their production and provision relies on several elements in a chain that accomplishes the delivery to a learner. A book, for example, is not just handed from the author to the reader; the delivery relies (at least) on a publisher, production facilities with a printing plant, a distributor and a bookstore. In the digital age, this complex value creation chain is challenged. But it would be naïve to think that when a teacher puts a resource "on the web" for others' there are no intermediary entities - private or public institutions - that eventually are responsible for making this resource retrievable on the net. Now, the production chain is less visible and the processing is experienced as seamless but from a larger view the network behind the network decides, for example, if and how these resources will be found by others, if and how they interconnect with other resources and services, how they eventually reach a class and how changes or enhancements to an (open) resource will be traced back. Therefore, the discussion about open educational resources and open education sometimes oversees the relevance of these intermediary services and how they operate.

In the following paper, we want to outline how the design of an informational ecosystem on the internet is shaping future education. For this, we will rely on the metaphor of an ecosystem which leans on a concept that has gained some prominence in the world of IT business. So far, IT companies often have tried to gain control over all elements of products, services and appliances they offer, but now they increasingly seek to create a product world that attracts other suppliers to offer additional goods that enhance the attractiveness of the initial product. The core company and its followers to some degree develop a mutual dependency and responsibility for this ecosystem that eventually gains value over time.

Inscribed in these ecosystems are tendencies to open as well as to close their boundaries. A successful ecosystem, for example, must be open enough to encourage possible partners to invest in the development of new products and services and it must be close enough to secure streams of revenue and to keep its identity. With its variety of services, such an ecosystem should keep a user within its boundaries and profit from lock-in effects which refers to the phenomenon that users once embraced - tend to stay within an ecosystem and not turn to other - maybe better products in a different ecosystem.

For this, we will explain ecosystems as infrastructures that make educational resources available to teachers and students. We will differentiate weak and strong OER to show the implications for the design of an informational ecosystem. Finally, mechanisms of open and closed informational ecosystems for education are introduced and their relationship to OER and OE is discussed.

This work is licensed under a Creative Commons Attribution 4.0 International License. 


\section{Weak and Strong OER}

As Tuomi (2013) has pointed out, there are various understandings of "open" educational resources. They do agree that OERs are digital artefacts that can be used free of (additional) costs. This can be called a "weak" definition of OER and includes all kind of materials and licenses. This view focuses on availability and accessibility as essential criteria. Other definitions add various criteria. The definition from OECD (2007) refers to "digitised materials offered freely and openly for educators, students, and self-learners to use and reuse for teaching, learning, and research. OER includes learning content, software tools to develop, use, and distribute content, and implementation resources such as open licences" (p.10).

A "strong" definition refers to practices of sharing and includes the right to edit, remix and reshare materials. Hilton III et al. (2010) framed the "4Rs" that can be drawn for such a definition of OER (cf. Table 1). Tuomi (2013) distinguished OER I (using), OER II (receiving credits), OER III (editing) and OER IV (redistributing). Activists of an "OER movement" stress the point that OER should grant these more extensive rights to foster a culture for sharing. In this line of reasoning, OERs are often seen as an agent for an educational vision where teachers actively participate in a mutual exchange of ideas and artifacts. However, de los Arcos et al. (2014) report that licences for these advanced use cases are not yet a primary concern for teachers and currently, only a fraction of teachers are willing to share their materials publicly (less than $3 \%$ in a study from Schuwer et al, 2014). Pirkkalainen, J okinen and Pawlowski (2014) have analysed the motivation of teachers to share materials in OER-repositories in more depth. Major barriers are a lack of organizational support, language and culture barriers as well as quality concerns.

This work is licensed under a Creative Commons Attribution 4.0 International License. 
Table 1

Weak and Strong OER

\begin{tabular}{|c|c|c|}
\hline & Weak OER & Strong OER \\
\hline Goal & $\begin{array}{l}\text { Dissemination of } \\
\text { knowledge }\end{array}$ & (Re-)generation of knowledge \\
\hline $\begin{array}{l}\text { Defining } \\
\text { criteria }\end{array}$ & $\begin{array}{l}\text { the " } 2 \text { A" } \\
\text { - Availability: to make } \\
\text { content publicly } \\
\text { available (without } \\
\text { additional cost for the } \\
\text { learner) } \\
\text { - Accessibility: to } \\
\text { reduce technical } \\
\text { barriers of access }\end{array}$ & $\begin{array}{l}\text { the " } 4 \mathrm{R} \text { " } \\
\text { - } \quad \text { Reuse: right to reuse content in its } \\
\text { unaltered form } \\
\text { - } \quad \text { Revise: right to alter content } \\
\text { - } \quad \text { Remix: right to combine the (altered) } \\
\text { content or parts hereof with other } \\
\text { content to create something new } \\
\text { - } \quad \text { Redistribute: right to share copies of } \\
\text { (revised) content or remixes to others }\end{array}$ \\
\hline $\begin{array}{l}\text { Typical } \\
\text { licenses }\end{array}$ & $\begin{array}{l}\text { copyright } \\
\text { copyleft } \\
\text { (semi-) free licenses } \\
\ldots\end{array}$ & $\begin{array}{l}\text { "creative commons licenses" } \\
\text { you may use, but } \\
\text { - you have to state the author (attribution) } \\
\text { - no commercial use allowed (non } \\
\text { commercial) } \\
\text { - editing is not allowed (no derivates) } \\
\text { - re-publishing / sharing is allowed only } \\
\text { under the same license (share alike) } \\
\text { public domain }\end{array}$ \\
\hline $\begin{array}{l}\text { Typical } \\
\text { cases }\end{array}$ & $\begin{array}{l}\text { e.g. data that shall not be } \\
\text { modified: demographic } \\
\text { data about Germany form } \\
\text { the "Federal Statistics } \\
\text { Office" }\end{array}$ & $\begin{array}{l}\text { e.g. a worksheet on fractions provided by a } \\
\text { teacher }\end{array}$ \\
\hline
\end{tabular}

The discussion of OER often does not clearly distinguish various levels of granularity: OER can comprise a wide range of artifacts from a single photo to a complete instructional set for a semester or school year comprising of a text and workbook with an accompanying interactive website, audiovisual material or training units. Weller (2011) distinguishes little OERs, individually produced low-cost resources, and big institutionally generated OERs. The following table shows the most typical use cases discussed as OERs. 
Table 2

Granularity of OER

\begin{tabular}{|c|c|c|c|c|}
\hline $\begin{array}{l}\text { Granular } \\
\text { level }\end{array}$ & Description & Coverage & $\begin{array}{l}\text { Provided by } \\
\text { (typically) }\end{array}$ & Examples \\
\hline Textbook & $\begin{array}{l}\text { a collection } \\
\text { of learning } \\
\text { units } \\
\text { may also } \\
\text { include } \\
\text { additional } \\
\text { materials, } \\
\text { like } \\
\text { workbook, } \\
\text { testbank, } \\
\text { CD-ROM or } \\
\text { website }\end{array}$ & $\begin{array}{l}\text { covering a } \\
\text { school year / } \\
\text { a semester / a } \\
\text { course, based } \\
\text { on a (state) } \\
\text { curriculum } \\
\text { (with } \\
\text { standards) }\end{array}$ & $\begin{array}{l}\text { book } \\
\text { publisher }\end{array}$ & $\begin{array}{l}\text { open.bccampus.com } \\
\text { collegeopentextbooks.org } \\
\text { wikibooks.org }\end{array}$ \\
\hline $\begin{array}{l}\text { Learning } \\
\text { unit }\end{array}$ & $\begin{array}{l}\text { related to a } \\
\text { topic / a } \\
\text { competence / } \\
\text { a set of } \\
\text { learning } \\
\text { objectives, } \\
\text { consisting of } \\
\text { several } \\
\text { elements, } \\
\text { like text, } \\
\text { exercises, } \\
\text { tests etc. }\end{array}$ & $\begin{array}{l}\text { a set of } \\
\text { associated } \\
\text { lessons / } \\
\text { learning } \\
\text { activities } \\
\text { lasting several } \\
\text { hours or } \\
\text { weeks, may } \\
\text { include lesson } \\
\text { plan, tests, } \\
\text { but does not } \\
\text { typically } \\
\text { result in a } \\
\text { (final) grade / } \\
\text { credit }\end{array}$ & $\begin{array}{l}\text { foundations, } \\
\text { universities, } \\
\text { associatons, } \\
\text { companies } \\
\text {... }\end{array}$ & $\begin{array}{l}\text { sharemylesson.com } \\
\text { tes.co.uk }\end{array}$ \\
\hline $\begin{array}{l}\text { Learning } \\
\text { material }\end{array}$ & $\begin{array}{l}\text { related to a } \\
\text { single } \\
\text { learning } \\
\text { objective / } \\
\text { learning } \\
\text { activity, e.g. a } \\
\text { worksheet } \\
\text { with one or } \\
\text { several } \\
\text { exercises, a } \\
\text { test, a } \\
\text { simulation }\end{array}$ & $\begin{array}{l}\text { a single } \\
\text { learning } \\
\text { activity } \\
\text { typically } \\
\text { completed } \\
\text { within a } \\
\text { certain time } \\
\text { frame (e.g. a } \\
20 \text { min. } \\
\text { exercise) }\end{array}$ & $\begin{array}{l}\text { foundations, } \\
\text { universities, } \\
\text { associations, } \\
\text { companies }\end{array}$ & $\begin{array}{l}\text { merlot.org } \\
\text { oercommons.org } \\
\text { oerafrica.org }\end{array}$ \\
\hline $\begin{array}{l}\text { Learning } \\
\text { asset }\end{array}$ & $\begin{array}{l}\text { a document, } \\
\text { e.g. a single } \\
\text { photo, video, } \\
\text { that may be } \\
\text { used for } \\
\text { instruction; } \\
\text { in HE: also } \\
\text { scientific } \\
\text { papers, data } \\
\text { sets }\end{array}$ & $\begin{array}{l}\text { a single } \\
\text { artifact, most } \\
\text { often not } \\
\text { produced } \\
\text { with an } \\
\text { educational } \\
\text { intention / for } \\
\text { an } \\
\text { instructional } \\
\text { use }\end{array}$ & anybody & commons.wikimedia.org \\
\hline
\end{tabular}

This work is licensed under a Creative Commons Attribution 4.0 International License. 
A major aspect of the current discussion are learning materials that teachers always have produced for homework and exercises in their classes. Teachers often include assets they find on the net or from other sources. With the internet, it is technically easy to make these materials available for a larger public. Many repositories exist where teachers can upload their materials and share them with others. Some of these repositories are confined to certain topics and then are sometimes maintained with the help of an associated institution; others cover all topics relevant for education and then are most often run by public agencies or private companies. The production of educational resources with a higher granularity (i.e., textbooks) that typically relate to a certain curriculum is a more complex enterprise.

\section{Informational Ecosystems}

Informational ecosystems relate to a network of connected servers or services on the internet that conjointly or cooperatively establish an environment for finding and providing informational resources to a larger public. This includes functions for the delivery of content and all related, more or less complex, functions of a value chain, like generating, editing, assembling, annotating, tagging, commenting or linking information resources. In such an ecosystem, several providers are linked to each other; their collaboration relies on standards to interface content and metadata.

Open informational ecosystems allow for any provider of contents to "plug into" the ecosystem by providing meta-data that can be retrieved from a reference platform (also called "referatory"). Closed informational ecosystems aim at restricting access to contents and meta-data within the boundaries of an ecosystem and locking users within these boundaries. Such a system can consist of a one-stop solution that combines all the described functions. But it can also be a network of confederated servers that jointly keep the boundaries of the system close.

In general, all informational ecosystems imply mechanisms for opening and closing. This essentially has to do with the dual nature of knowledge and information: The perspective of information economy is viewing information as a somewhat tangible asset that can be monetized - if access to the information can be restricted. The perspective of information ecology, on the other hand, is viewing information as a good that gains value by diffusion and by increasing access (Kuhlen, 2012).

Information can be seen as a lasting good that is owned as an entity that can be given to others as barter or as a donation. These goods can be valorized if a mechanism exists that allows restricting and controlling access and distribution. In this view, one would try to restrict and control access to knowledge which can be achieved by various measures, like hiding knowledge (e.g., behind organizational walls), by imposing legal, financial or technical restrictions (e.g., patents, trademarks or licensing schemata, digital rights management). This process is based on a more

This work is licensed under a Creative Commons Attribution 4.0 International License. 
complex value chain that relies on the expertise of several professionals (expertise in legal issues, marketing, publishing, production ...).

Information can also be perceived as a non-lasting good that can be shared freely, like emotions (love, hate, happiness) or cultural practices or religious ideas. These goods gain value if they are shared with others and receive attention from others. In this view, one would try to loosen restrictions on the accessibility of knowledge that can be disseminated to the public, for example by making it freely available on the internet. As an author, one may gain reputation if one's ideas are shared widely and one may receive recognition for one's insights. With the internet, the dissemination of knowledge to a larger public has become rather simple and is less dependent on the availability of additional expertise. Such a broad dissemination of knowledge had always been associated with high investments and therefore was limited. With the easy ways to communicate knowledge over the internet traditional business models of valorizing knowledge have been questioned. Richter and Veith (2014) describe changes in the value creation chain in the production of digital assets for learning. Tuomi (2013) points out that some goods even enhance their value the more people have access to them and the more they are being used. OER can be described as such "open fountains of goods".

Some authors have claimed that innovation relies on the possibility of an inventor / author to protect and to monetarily exploit his/her works. Others claim that a society does prosper only when knowledge essentially is public and widely made available. Basically, any modern society needs both mechanisms, the opening and closing of information, and needs to find the right balance between them. This balance should align with cultural traditions, values and visions for the future. For example, to develop new technologies a company will invest in research and eventually will seek to patent inventions to be able to monetize their investments (i.e., closing access). However, to develop and to apply these patents the company has to rely on an educated workforce with all necessary skills a culture has accumulated and that are conveyed via schools and instruction (i.e., opening access).

Both views of knowledge and both mechanisms of informational ecosystems should be perceived as cultural achievements that are responsible for many innovations. Balancing the two is a continuous process of discourse in a society. It becomes especially important when new technologies or business models arise that question cultivated practices (Kuhlen, 2012).

The most obvious mechanism of closure is the application of a pay wall that restricts access via pay per view or pay per subscription. Also, a need for registration on a website sometimes is perceived as a mechanism of "closure" because it restricts the immediate access to a resource; the user - at least - has to pay with some personal information, for example an email address. It is argued, that some instructional approaches necessitate a registration, for example when a highly interactive site consists of elements of editing, sharing, commenting. However, hiding information behind some wall may be viewed critically because the dissemination of the material

This work is licensed under a Creative Commons Attribution 4.0 International License. 
is severely hampered. Search engines in most cases will not be able to find the resources behind such a (pay or registration) wall.

A further step of closing information is technically restricting access to certain operating systems, devices, protocols or formats. With this, the user experience basically can be enhanced because the systems provider can control the elements of the environment and can, for example, ensure that certain elements of a user interface are systematically applied all over the various applications, tools and devices. In an extreme case, instructional applications built with a certain tool from one company can only be used with certain devices from this company. Again, this scenario might deliver a smooth user experience with the drawback that the use is limited to certain devices. Societies differ in the emphasis they put on closing or opening of information: For example, a society that strongly believes in the transformative power of innovations from private enterprises would more strongly support mechanisms of closing information than a society that is emphasizing the equality of access, solidarity and public discourse. Also, more authoritarian systems prefer mechanisms of closing information that allow state authorities larger control to the dissemination and accessibility of information.

Mechanisms of opening information relate to several dimensions: Foremost and first of all, free access to materials for learners is the most important and apparent aspect of open education. However, there are many more aspects relevant in this discussion. The resource should be accessible and therefore use formats and protocols that are openly available. It is discussed if proprietary formats for documents, like Adobe PDF or Microsoft Word DOC, would seem acceptable under this category. However, from the perspective of a teacher these formats seem convenient and can easily be integrated into their workflow. Opening information would also relate to the technology the information is made available with: Does the resource provide a rich set of meta-information that simplifies retrieval? Can the resource be accessed by advanced mechanisms, like feeds or web services?

\section{Constituents of Informational Ecosystems for Education}

Educational resources "live" in an environment that has been described as an informational ecosystem. It has to provide at least three basic functions:

a) a teacher searches for educational resources, e.g., at a reference platform;

b) that links to a resource on a content platform;

c) that provides content for a learning platform.

This work is licensed under a Creative Commons Attribution 4.0 International License. 
To find a reference to a material the teacher might use a generic search engine (like Bing) or, more probably, will visit a platform that aggregates links to various providers. It should provide a semantically richer search environment with meta-data that make it easier to find the needed resource. The content platform typically is a repository where materials can be downloaded or bought, in order to be used on a school platform.

These three basic functions can be implemented in a one-stop solution where teachers can search for materials, find contents and make them available for their classes. Such a solution provides some advantages because teachers and students find all functions on a single platform (and closed informational ecosystems tend to provide all functions under the umbrella of such a one-stop solution). However, often relevant materials are spread over several platforms, servers and institutions. There are many providers of (closed and open) contents for learning, and schools have their own (instances of a) learning platform, where private data of their students are kept safely. Therefore, an open informational ecosystem most typically relies on a network of confederated servers from several independent suppliers.

These three basic functions implement demands of a weak OER approach that focuses on the provisioning and retrieval of resources. A strong OER approach still is based on the same functions but here the teacher contributes actively by returning new or modified resources or meta-data to the system (links, tags etc.). Figure 1 shows how strong OER relies on contributions of the teacher who feeds back information into the system. This follows the current model of Web 2.0, which shows how users increasingly become authors in the internet.

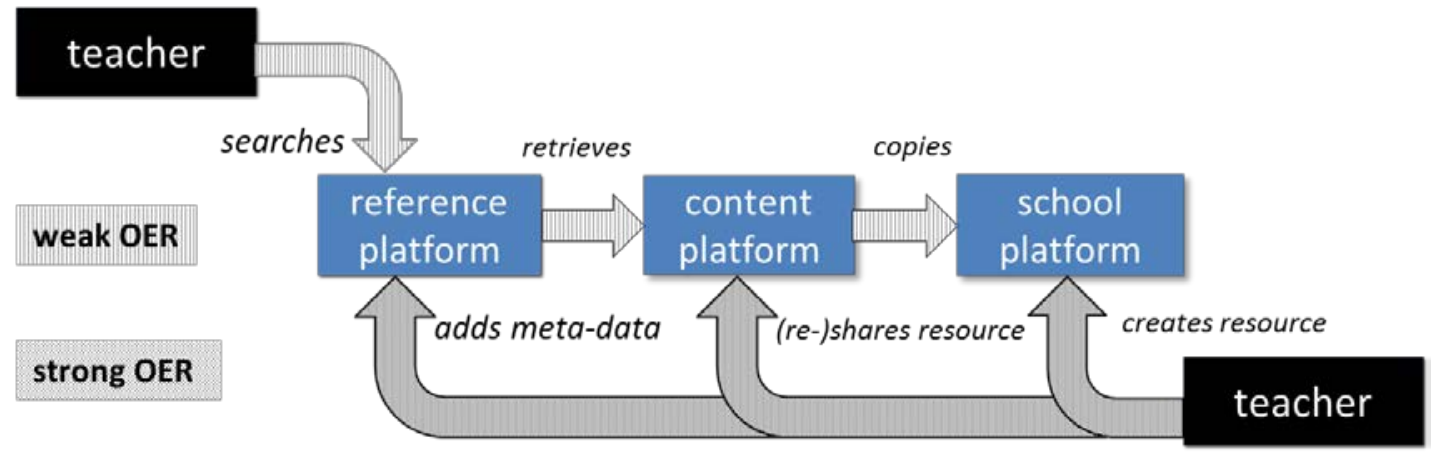

Figure 1. Elements of an informational ecosystem with weak and strong OER.

In an open informational ecosystem, the reference platform plays a crucial role. It acts as a gateway to all the associated content platforms which makes it attractive for a teacher to visit. In general, a reference platform links to contents and provides additional meta-data that helps the teacher to find materials. The meta-data can result from three sources: 
- editorial staff (employed by a private or public institute),

- $\quad$ user generated contents (provided by teachers), or

- web mining (based on the automated extraction of meta-data from content platforms).

Some reference platforms for educational resources, if available, are run by state authorities, foundations or other public or private institutes; the editorial staff consists of teachers that are engaged - full or part time - to find and evaluate educational resources they find on the net. Other platforms rely on contributions from teachers, who voluntarily add their findings. Web mining technologies are used to automatically extract information from contents that can be retrieved from the net; for example, such a robot can discover automatically if a resource is provided with a CClicense.

In the best case, all three elements are combined to establish an efficient platform with many resources of high quality. Web mining delivers the broadest and easiest entrance for catching materials from content providers. User generated contents from teachers are a most valuable source, especially for enhancing the links with educational meta-data. An editorial team, finally, is important to correct and to enrich contributions. Furthermore, in an open informational ecosystem the reference platform must contain a mechanism to allow for the exchange of its meta-data with other reference platforms.

In Germany, the (publicly financed) Deutsche Bildungsserver (German Educational Server: www.eduserver.de) acts as a reference platform that links to private and public content providers with (open and closed) learning materials for primary and secondary education. With ELIXIER', an exchange format for meta-data on learning materials, the server is linked with reference platforms from (most of) the 16 German states that themselves run such services for their teachers. In the future, this exchange mechanism will be opened to other content providers that want to contribute and / or retrieve links to educational resources. It is the idea, that in this federation of platforms, the various providers of educational resources will not compete against each other by trying to establish closed ecosystems but eventually will win if they contribute to the joint network of OER-repositories.

Edutags.de, as part of the Deutsche Bildungsserver, acts as a social bookmarking tool where teachers provide links (with tags) to useful resources on the net. As with similar services, the majority of users is interested in finding, retrieving and downloading materials and is not (yet) actively participating in providing new or contributing to existing information. However, some low level mechanisms, like simple evaluation schemas (e.g., a five-star rating) or leaving short comments, receive broader acceptance (Kerres \& Heinen, 2014). In the future, these teachergenerated metadata will be merged with information from the editorial staff of the educational

\footnotetext{
${ }^{1}$ http://www. bildungsserver.de/elixier/elixier.pdf

This work is licensed under a $\underline{\text { Creative Commons Attribution } 4.0 \text { International License. }}$
} 
servers in the ELIXIER-network as well as automatically generated meta-information that are extracted from the resource by textmining (Heinen et al, 2014).

\section{The Open-Fallacy}

After having outlined elements of an informational ecosystem we want to address how it contributes to the broader goal of "opening up education" (Conole, 2012; Willems \& Bossu, 2012). Despite the long history of open education (cf. Peter \& Deimann, 2013), we just want to refer to the mission of the Open University UK to "be open to people, places, methods and ideas"2, which demonstrates the broad understanding of openness and its linkage to societal issues. Educational equity, fairness and inclusion, caring for the diversity of learners, open curricula and social responsibility are some of the keywords in this discussion. Still, we often are faced with a somewhat simple equation that assumes that having (many) educational resources with an open license will lead to the opening of education. However, the relationship between OER and open education is more complex: Open education can profit from closed as well as from open educational resources. Open educational resources are not inherently and directly related to the opening of education. And: "Both sharing and openness tend to have positive associations, particularly in OER environments. However, this should not keep us from remembering that both of these terms do not per se represent values" (Hug, 2014).

${ }^{2}$ The Open University. 2008. About the OU: Our mission Retrieved June 18, 2008 , fromhttp://www.open.ac.uk/about/ou/p2.shtml

This work is licensed under a Creative Commons Attribution 4.0 International License. 


\begin{tabular}{|c|c|c|}
\hline $\begin{array}{l}\text { educational } \\
\text { resources }\end{array}$ & ecosystems & education \\
\hline $\begin{array}{l}\text { open } \\
\text { - availability } \\
\text { - accessibility } \\
\text { - reuse } \\
\text { - revise } \\
\text { - remix } \\
\text { - reshare }\end{array}$ & $\begin{array}{l}\text { open } \\
\text { - connected systems } \\
\text { - distributed functions } \\
\text { - decentralized control } \\
\text { - metadata exchange } \\
\rightarrow\end{array}$ & $\begin{array}{l}\text { open } \\
\text { - educational equity } \\
\text { - social justice } \\
\text { - widening participation } \\
\text { - new target groups } \\
\text { - caring for diversity } \\
\text { - individualized learning } \\
\pi^{-} \text {social responsibility }\end{array}$ \\
\hline $\begin{array}{l}\text { close } \\
\text { shorting access to a } \\
\text { single resource by } \\
\text { - legal barriers } \\
\text { - financial barriers } \\
\text { - technical barriers }\end{array}$ & $\begin{array}{l}\text { close } \\
\text { shorting access to a } \\
\text { network of resources } \\
\text { - legal barriers } \\
\text { - financial barriers } \\
\text { - technical barriers } \\
\rightarrow\end{array}$ & $\begin{array}{l}\text { close } \\
\text { shorting access to } \\
\text { educational chances by } \\
\text { - legal barriers } \\
\text { - financial barriers } \\
\text { - technical barriers } \\
\rightarrow\end{array}$ \\
\hline
\end{tabular}

Figure 2. Relationship between open educational resources, informational ecosystems and education.

Although counterintuitive at first sight, having "free access" (even if desirable) does not automatically lead to higher degrees of participation or inclusiveness. The German education system, for example, provides free (or subsidized) access to education on all levels of education resulting in a system where most students of all ages learn in public institutions. And still, the German system is criticized as one of the most highly selective systems privileging students from parents with an academic background: In comparison with other industrialized countries, there is a high correlation between the academic degree of parents and their children (OECD, 2012).

The proliferation of (open) educational resources will not change educational practices and will not improve education somewhat automatically (for more critical aspects see Knox, 2013). The sheer existence of open resources alone will not be sufficient to enhance education and to widen educational participation. Weller (2013) points out that the discussion has moved from 'do you want to be open?' to 'what type of openness do you want?'. Stacey (2013) analyzed OER-policies in different countries. All of them are concentrating on the production and distribution of OERs. From our perspective, a further shift is needed to focus on the infrastructural conditions that support the proliferation of OERs. 
The increasing number of competing OER-repositories will need to establish mechanisms to exchange their materials more easily in order to increase the base of high quality materials that can more easily be retrieved by teachers. Currently, OER-repositories collect openly licenced materials but in effect are not openly connected via interfaces that provide meta-data about the resources available. The Learning Resources Metadata Initiative (LRMI) - led by the Association of Educational Publishers \& Creative Commons - could be helpful in establishing a network of linked content providers (cf. Piedra et al, 2014). Future research will be needed to analyse the concrete potential of exchange formats and mechanisms to build federated systems of networked platforms to establish open informational ecosystems. We have argued that a coherent infrastructure for learning will be needed to develop and disseminate OER adequately in an open informational ecosystem. As Mulder (2013) has pointed out, (inter-)national policies are needed for a sustainable implementation of OER practices.

We have described the informational ecosystem as the important - and often missing - link between educational resources and the educational system. Informational ecosystems can be open or closed, and both can rely on open or closed educational resources. Therefore, the relationship between these levels of analysis has to be seen as more complex and there are no immediate causal relations between the different levels. In order to fulfill the potential of OER, we will need to gain a better understanding of how to design informational ecosystems for learning and how they contribute to the opening of education. 


\section{References}

Conole, G. (2012). Fostering social inclusion through open educational resources (OER). Distance Education, 33(2), 131- 134. doi:10.1080/01587919.2012.700563

delos Arcos, B., Farrow, R., Perryman, L.-A., Pitt, R. \& Weller, M. (2014). OER evidence report 2013-2014. OER Research Hub. Available from http:// oerresearchhub.org/about2/reports/

Heinen, R., Blees, I., Kerres, M. \& M. Rittberger (2014). Open educational resources and social bookmarking: Connecting users and editors. In C. M. Stracke, U.D. Ehlers, A. Creelman \& T. Sharamina-Heidenreich (Eds.) Changing the trajectory - Quality for opening up education. Official Proceedings of the International EIF / LINQ Conference 2014 held in Crete, Greece, 7th -9th of May 2014.

Hilton III, J ., Wiley, D., Stein, J ., \& J ohnson, A. (2010). The four "R"s of openness and ALMS analysis: Frameworks for open educational resources. Open Learning: The J ournal of Open, Distance and e-Learning, 25(1), 37-44. doi:10.1080/02680510903482132

Hug, T. (2014). Education for all revisited: On concepts of sharing in the open educational resources (OER) movement. Seminar.net, 10(1) http:// www.seminar.net/images/stories/vol10-issue1/Theo_Hug_Education-forall Essay.pdf

Kerres, M. \& R. Heinen (2014). Open educational resources and informational ecosystems: Edutags as a connector for open learning. MedienPaed. In Friesen, N., Hug, T. \& D. Meister (Eds.), Educational Media Ecologies, 24, 154- 173, Retrieved from http:// www.medienpaed.com/24/\#kerres heinen1410

Knox, J . (2013). Five critiques of the open educational resources movement. Teaching in Higher Education, 18(8), 821- 832. doi:10.1080/ 13562517.2013.774354

Kuhlen, R. (2012) Knowledge is the water of the mind. How to structure rights in immaterial commons. In D. Bollier \& S. Helfrich (Eds.), The wealth of the commons. A world beyond market \& state. The Commons Strategies Group. Amherst, MA.

Mulder, F. (2013). The logic of national policies and strategies for open educational resources. The International Review of Research in Open and Distance Learning, 14(2), 96- 105.

OECD. (2007). Giving knowledge for free: The emergence of open educational resources. OECD Publishing. 
OECD. (2012). Equity and quality in education: Supporting disadvantaged students and schools. OECD Publishing. http:// dx.doi.org/ 10.1787/ 9789264130852-en

Piedra, N., Chicaiza, J . A., López, J ., \& Tovar, E. (2014). An architecture based on linked data technologies for the integration and reuse of OER in MOOCs context. Open Praxis, 6(2), 171- 187. doi:10.5944/ openpraxis.6.2.122

Pirkkalainen, H., J okinen, J ., \& Pawlowski, J . (2014). Understanding social OER environments: A quantitative study on factors influencing the motivation to share and collaborate. IEEE Transactions on Learning Technologies, PP(99), 1- 1. doi:10.1109/TLT.2014.2323970

Peter, S., \& Deimann, M. (2013). On the role of openness in education: A historical reconstruction. Open Praxis, 5(1), 7- 14. doi:10.5944/ openpraxis.5.1.23

Richter, T., \&Veith, P. (2014). Fostering the exploitation of open educational resources. Open Praxis, 6(3), 205-220. doi:10.5944/ openpraxis.6.3.139

Schuwer, R., Kreijns, K., \&Vermeulen, M. (2014). Wikiwijs: An unexpected journey and the lessons learned towards OER. Open Praxis, 6(2), 91- 102. doi:10.5944/ openpraxis.6.2.116

Stacey, P. (2013). Government support for open educational resources: Policy, funding, and strategies. The International Review of Research in Open and Distance Learning, 14(2), 67-80.

Tuomi, I. (2013). Open educational resources and the transformation of education. European J ournal of Education, 48(1), 58- 78. doi:10.1111/ ejed.12019

Weller, M. (2011). The digital scholar: How technology is changing academic practice. Bloomsbury Publishing PLC. Retrieved from https:// www.bloomsburycollections.com/ book/ the-digital-scholar-how-technology-istransforming-scholarly-practice/

Weller, M. (2013). The battle for open - a perspective. J ournal of Interactive Media in Education, 2013(3), 15. doi:10.5334/2013-15

Willems, J ., \& Bossu, C. (2012). Equity considerations for open educational resources in the glocalization of education. Distance Education, 33(2), 185- 199. doi:10.1080/01587919.2012.692051 
Open Informational Ecosystems: The Missing Link for Sharing Educational Resources

Kerres and Heinen

(C) Kerres and Heinen

\section{Athabasca University}

(c) (7)

This work is licensed under a $\underline{\text { Creative Commons Attribution } 4.0 \text { International License. }}$ 